\title{
Cláusulas antielusivas específicas y capacidad contributiva: a propósito de la limitación a la deducción de intereses
}

Jorge Otoya Cabrera

Abogado por la Universidad Privada Antenor Orrego.

SUMARI0:

I. Introducción.

II. Normas antielusivas específicas y capacidad contributiva.

III. Las limitaciones para la deducción de intereses en el contexto de BEPS.

IV. El cambio de enfoque en las reglas para la deducción de intereses, y su aplicación en Perú a partir de 2021. 


\section{RESUMEN:}

A través de este artículo, el autor desarrolla el cambio de enfoque en las reglas para la deducción de intereses como consecuencia del cambio normativo que se dio en el año 2019 con relación a la aplicación de la norma antielusiva así como su aplicación en el Perú a partir del año 2021.

Palabras clave: Norma antielusiva, deducción de intereses, BEPS, capacidad contributiva y EBITDA

\section{ABSTRACT:}

In this article, the author develops the change of focus in the rules for the deduction of interest as a consequence of the regulatory change that occurred in 2019 with regard to the application of the anti tax avoidance law as well as its application in Peru as of 2021.

Keywords: Anti-avoidance rule, interest deduction, BEPS, taxable capacity and EBITDA

\section{INTRODUCCIÓN}

En 2019, se aprobaron y publicaron las disposiciones complementarias para la aplicación de la norma antielusiva general -en adelante, la GAAR - la que, en nuestro país, se encuentra contenida en los párrafos segundo y tercero de la Norma XVI del Título Preliminar del Código Tributario.

Según dicha norma, que define y busca sancionar lo que se denomina "elusión fiscal", ésta se presenta cuando el contribuyente, con la finalidad de obtener una ventaja tributaria, emplea estructuras legales que, aun cuando produzcan los efectos buscados por él, no sean las que se hubieran empleado usualmente para conseguirlos, o se empleen para una finalidad distinta a aquella para las que fueron creadas. Así, con la GAAR se busca sancionar el ahorro no lícito - es decir, no admitido por el ordenamiento jurídico- de tributos, o, en palabras del profesor García Novoa', la "búsqueda del hecho no gravado -o del hecho menos gravado- $a$ través de un negocio anómalo".

\section{NORMAS ANTIELUSIVAS ESPECÍFICAS $Y$ CAPACIDAD CONTRIBUTIVA}

No ha sido extraña, en nuestra legislación, la introducción de normas antielusivas específicas, lo que ha sido consecuencia de la detección de estrategias empleadas por los contribuyentes con el objeto de minimizar o neutralizar la carga tributaria que soportaban. Así, por ejemplo, tenemos la incorporación, en 1991, como supuesto gravado con el IGV de la primera venta de inmuebles edificados por el constructor - para evitar la elusión en los contratos de construcción-, pasando por el impedimento a la deducción de gastos incurridos con contrapartes residentes en países o territorios de baja o nula imposición - vigente desde el 2001-, hasta la recalificación, como venta, de transferencias de activos ocurridas en el marco de procesos de escisión, ocurrida a consecuencia de la reforma introducida en la Ley del Impuesto a la Renta a partir del 1 de enero de 2013.

Con referencia a este tipo de normas, Heleno Taveira Torres" ${ }^{2}$ quien las denomina "normas de prevención" o de "corrección", nos indica que "(...) no son normas propiamente antielusivas", aún cuando suela llamárseles así, de modo coloquial. Indica que, más bien,

"son formas de tipificación de los actos o negocios sujetos a efectos elusivos, que buscan alcanzar el respectivo control al amparo del

1. César García Novoa, La Cláusula Antielusiva en la Nueva LGT (Madrid: Marcial Pons Ediciones Jurídicas y Sociales, 2004), 131.

2. Heleno Taveira Torres, Derecho Tributario y Derecho Privado. Autonomía Privada, simulación y elusión tributaria (Buenos Aires: Marcial Pons, 2008), 235. 
principio de legalidad, de manera preventiva, al prohibir el uso de ciertos beneficios fiscales, ampliar el concepto de materia imponible o limitar el uso de créditos, etcétera".

En otras palabras, a través de este tipo de normas, el legislador asigna a un determinado hecho económico una consecuencia legal distinta a la que le hubiera correspondido, por su naturaleza, de aplicarse el marco legal general. Así, estas normas prescinden total o parcialmente de la realidad económica para asignar a los actos, situaciones y relaciones jurídicas llevadas a cabo por los contribuyentes determinadas consecuencias estimadas por el legislador como "no elusivas", pues impiden el menoscabo de la recaudación.

En nuestro país, no son pocas las oportunidades en las que el Tribunal Constitucional se ha pronunciado acerca de la legitimidad, desde el punto de vista constitucional, de medidas que tienen por objeto combatir situaciones de elusión y/o evasión tributaria, si bien no ha tenido oportunidad, aún, de pronunciarse acerca de la constitucionalidad de una norma antielusiva específica.

Así, por ejemplo, en el caso del sistema de detracciones ${ }^{3}$, justificó su aplicación en el principio de igualdad, bajo el argumento que están permitidas las diferencias en el trato fundadas en la consecución de un fin constitucionalmente legítimo, siempre que las consecuencias jurídicas derivadas del tratamiento diferenciado sean proporcionales a la finalidad perseguida, de manera que los resultados terminen siendo excesivamente gravosos o desmedidos. Sin embargo, en la sentencia 06089-2006-PA/ $\mathrm{TC}^{4}$, expedida con motivo de la evaluación de la constitucionalidad del sistema de percepciones, el Tribunal Constitucional reconoció que la posibilidad de introducir en nuestra legislación este tipo de medidas "(...) no significa que el
Legislador o la Administración Tributaria tengan carta abierta para sustentar su aplicación apelando de manera indiscriminada a la extrafiscalidad en la lucha contra la evasión tributaria", en otras palabras, está permitida "(...) la relativización del principio de capacidad contributiva, mas nunca su desaparición total."

Esta, precisamente, es la cuestión que nunca debe perderse de vista al momento en que se emiten normas antielusivas específicas, y que nos lleva a preguntar si el cumplimiento del doble fin que persiguen éstas; el cual es, de un lado, evitar la minimización o neutralización de la carga tributaria y así, del otro, poder garantizar que todos contribuyan al sostenimiento del erario según su real capacidad contributiva, sin terminar afectando a esta última, de manera desproporcionada e irracional.

\section{LAS LIMITACIONES PARA LA DEDUC- CIÓN DE INTERESES EN EL CONTEXTO DE BEPS}

En nuestro país, a consecuencia de la entrada en vigor de la Ley 27356 en 2001, se encontraba restringida la deducción de los intereses del endeudamiento con partes vinculadas, siempre que excediera del monto que resultase de la aplicación de un coeficiente fijado por el reglamento. Con dicha medida, se pretendía combatir la denominada "subcapitalización", conducta elusiva que, en palabras de Ramón Falcón y Tella y Elvira Pulido Guerra, ${ }^{5}$ hace referencia a aquellos supuestos en que

"los socios, en lugar de realizar aportaciones de capital, financian a la sociedad a través de préstamos, lo que supone que la sociedad tenga unos fondos propios (...) anormalmente reducidos en relación con su pasivo total (...)".

3. Sentencia del Tribunal Constitucional recaída en el Expediente N03769-2010-PA/TC, considerandos 35 y 39.

4. Considerando 29.

5. Ramón Falcón y Tella y Elvira Pulido Guerra, Derecho Tributario Internacional:Tercera Edición (Madrid: Marcial Pons Ediciones Jurídicas y Sociales, 2018), 293 y ss. 
Como bien indican estos autores, lo interesante de esta situación es que, de un lado,

"se trata de casos en que un tercero independiente (un banco ajeno al grupo, por ejemplo), en condiciones normales de mercado, no habría realizado el préstamo o habría prestado una cantidad inferior", y del otro, "tiene la ventaja de que los intereses que se pagan al socio son gasto deducible"t.

Suena, pues, razonable pensar que una entidad financiera independiente no habría estado dispuesta a prestar dinero a una empresa que carecía de capital suficiente para poder atender sus obligaciones, si no es porque percibe que cuenta con tal capital; aunque recibido como "deuda" y no como aportación al capital, siendo evidente que, en ambas situaciones, el accionista asume el mismo nivel de riesgo, esto es, no un riesgo de acreedor, sino el riesgo propio de un socio.

Si bien no contamos con evidencia numérica de los resultados conseguidos en los ya veinte períodos tributarios en que esta norma antielusiva específica se ha encontrado en vigor - contando, incluso, la modificación introducida en 2019, que amplió su espectro al endeudamiento con vinculadas-, podemos señalar, de modo empírico, que cumplía su función de modo adecuado, pues, ciertamente, combatía una cuestión en la que, como indicamos, se pretendía tomar una deducción de intereses como consecuencia del devengo de lo que no era otra cosa que un mecanismo de remuneración de capital propio de la sociedad. Es principio asumido en la mayoría de legislaciones tributarias que el capital propio de una sociedad no está sujeto a remuneración, ni mucho menos esta podría dar lugar a una deducción, salvo en casos puntuales como el de caso de Brasil con los juros sobre capital propio.
En 2015, como resultado de las iniciativas de la Organización para la Cooperación y Desarrollo Económicos - OCDE para combatir la erosión de bases imponibles y el desvío de rentas, se publicó el reporte final de la Acción 4, denominado "Limiting Base Erosion Involving Interest Deductions and Other Financial Payments". Bajo la premisa de reconocer que "algunos grupos están altamente apalancados con deuda con terceras partes por razones de índole distinta a la tributaria", en este reporte, la OCDE recomendó la introducción de una regla de ratio corporativo, junto con una de ratio fijo, a fin de permitir a una entidad "con intereses netos por encima de ratio fijo del país" deducir intereses hasta el nivel de la ratio intereses netos/EBITDA de su grupo de empresas. ${ }^{7}$

La OCDE ${ }^{8}$ recomendó, además, la introducción de tres medidas para morigerar los efectos de estas recomendaciones:

a) Un umbral mínimo, que excluya a entidades con bajo nivel de gasto por intereses.

b) Exclusión de los intereses pagados a terceros independientes en relación con préstamos empleados para financiar proyectos de fomento público, bajo ciertas condiciones.

c) El arrastre de aquellos intereses cuya deducción no fue permitida y/o de la capacidad de endeudamiento no utilizada, para su uso en años futuros.

IV. EL CAMBIO DE ENFOQUE EN LAS REGLAS PARA LA DEDUCCIÓN DE INTERESES, Y SU APLICACIÓN EN PERÚ A PARTIR DE 2021

Con base en la acción 4 de BEPS, el Decreto Legislativo 1424 introdujo, con vigor a partir del 1 de enero de 2021, un cambio de enfoque en

\footnotetext{
6. Ibíd, p. 293.

7. Ibíd, p. 13.

8. Ibíd, pp. 13 y 14 .
} 
las reglas para la deducción de intereses. Dejó de lado el empleo del patrimonio neto como referente para la identificación de situaciones de subcapitalización, esto es, de endeudamientos obtenidos en condiciones distintas a las de mercado, para pasar a emplear una base -en teoría, financiera-, computada con relación al EBITDA de la sociedad.

Si bien la exposición de motivos de dicho decreto legislativo nada dice con respecto a la justificación, en específico, de haber introducido una limitación a la deducción de intereses con base en el EBITDA de la compañía, sí indica, de modo general, las razones de la ampliación de la limitación a los intereses de endeudamientos con terceros ${ }^{9}$ :

a) La evidencia internacional señala que los contribuyentes pueden adoptar esquemas complejos en los que no es posible verificar si se están realizando operaciones entre partes vinculadas.

b) Algunos grupos internacionales reducen su carga tributaria total mediante el pago de intereses.

c) Existen indicios de que estas formas de endeudamiento se vienen realizando en nuestro país, pues empresas sin patrimonio o con bajas utilidades reciben préstamos desproporcionados.

De la lectura de estas justificaciones, no encontramos una que sustente por qué para el legislador delegado resultó adecuado, desde una perspectiva de proporcionalidad, que se extienda la limitación a la deducción de intereses a los devengados en endeudamientos con terceros, menos una que justifique que la base de cálculo de la limitación pase a ser una computada en consideración del EBITDA, y no del patrimonio, como ocurría hasta 2020.

Efectivamente, en cuanto a la primera y la se- gunda de las razones alegadas como sustento de la medida, si bien nadie podría negar que ciertos contribuyentes podrían haber implementado esquemas complejos de financiamiento para ocultar transacciones de traslado de beneficios hacia terceros vinculados, eso, desde ningún punto de vista, podría llevar a concluir, iuris et de iure que cualquier endeudamiento tiene finalidades elusivas y/o que encubre un mecanismo de planificación fiscal, ya que esto implicaría, necesariamente, el uso de varios actores y negocios jurídicos para poder alcanzar la traslación de beneficios que busca combatir esta norma y, en ese contexto, la adopción de este tipo de medidas estaría justificada solo si fuera imposible identificar a tales actores o esquemas, o si no es posible que el contribuyente acredite que el endeudamiento fue incurrido en condiciones de mercado.

En tiempos como los actuales en los que las autoridades tributarias pueden acceder a la información financiera de los contribuyentes, a través de mecanismos de intercambio de información o de levantamiento del secreto bancario, no parece adecuada la adopción, per se, de una medida de este tipo que, a ciegas, limite la capacidad de endeudamiento de una compañía y, con ello, sus expectativas de crecer e, incluso, de sobrevivir. Tampoco podría ser calificada de razonable o proporcional una medida como esta si es que no incluye, por lo menos, un mecanismo de prueba en contrario que permita acreditar la existencia de necesidad de endeudamiento, y si, además, no contempla excepciones amplias a su aplicación, que deben estar relacionadas con el tipo de endeudamiento y el tipo de acreedor. Volveremos sobre estos aspectos más adelante.

En cuanto a la tercera de las razones alegadas, debemos decir que el hecho de que, de modo indiciario, se pueda asumir que algunos contribuyentes adoptan mecanismos sofisticados de elusión a través del empleo de endeudamientos con terceros no es suficiente para desconocer, 
iuris et de iure, la realidad de aquellos endeudamientos y/o de la necesidad de financiamiento detrás de esos endeudamientos. Es principio en la lógica jurídica que no es posible, a partir de premisas individuales, arribar a una conclusión de carácter general.

Hasta aquí, puede concluirse a priori que ninguna de las razones mencionadas por el legislador delegado puede ser catalogada como suficiente para justificar la introducción de una medida tan extrema como la limitación de la deducción de intereses de endeudamientos reales en casos de financiamientos obtenidos de terceros. Surge, así, la necesidad de revisar si una medida como la que entró en vigor en 2021 constituye una afectación razonable a la capacidad contributiva de los contribuyentes.

Para responder a esa inquietud, debemos recordar qué grava el impuesto a la renta: la utilidad de un período tributario, que, en nuestro país, coincide con el año calendario. Para computar esa utilidad, no se consideran los gastos que no sean necesarios para la obtención de la renta gravada o el mantenimiento de su fuente generadora.

La regla que condiciona la deducción de un gasto a la existencia de una vinculación de necesidad con la obtención de una renta o el mantenimiento de su fuente no es otra cosa que una regla de gestión: de esa forma, el Estado asume, en los hechos, el papel de socio oculto y partícipe de la gestión de los contribuyentes, y exige el manejo eficiente de sus recursos, con el fin de obtener una adecuada participación en los resultados a través del impuesto a la renta que le corresponde. Se evita con ella, pues, que el Estado-socio asuma las consecuencias del empleo no diligente de recursos o que estos se destinen a fines distintos de los propios del giro de la empresa, tal como lo exigiría cualquier socio minoritario en el contexto de una sociedad o compañía bien gestionada.

Con esa premisa en mente, si bien resulta justificado condicionar la deducción de un gasto a que este sea necesario para obtener la renta gravada - pues, en definitiva, el impuesto gra- va la renta-, toda limitación a la deducción de gastos que sean necesarios para obtener las rentas gravadas o para mantener su fuente generadora tiene que fundarse en razones de última ratio, y debe cuidarse que, con su imposición, se causen perjuicios mayores que los beneficios fiscales y extrafiscales que se perseguía conseguir. En otras palabras, una regla de este tipo solo puede ser adoptada cuando ello sea inevitable, es decir, cuando no puedan implementarse otros mecanismos con los cuales se pueda cumplir con los mismos fines fiscales o extrafiscales.

Cuando nos referimos a la deducción de intereses, hablamos del tratamiento de la remuneración de los recursos financieros, elemento indispensable para el funcionamiento y la supervivencia de cualquier empresa y que, por ende, requiere del legislador tener sumo cuidado al momento de adoptar medidas que lo regulen. A diferencia de otras situaciones en nuestra legislación, como puede ser la relativa a la deducción de gastos de representación, respecto de los que sí puede ser adecuado, por lo menudo de su importe y el número de operaciones realizadas, fijar límites monetarios para la deducción, cualquier medida que limite, a ciegas, la deducción de intereses de financiamientos que sean necesarios para la obtención de rentas gravadas o el mantenimiento de su fuente será desproporcionada $-\mathrm{y}$, por ende, confiscatoria- si es que desconoce la deducción de intereses de financiamientos reales, y tal desconocimiento no está fundado en la realización real de prácticas elusivas por parte del contribuyente o, lo que es lo mismo, no se ha permitido al contribuyente demostrar lo contrario. En dichas situaciones, mal podría calificarse a esta medida como de última ratio.

Veamos, a continuación, cómo las disposiciones contenidas en el Decreto Legislativo 1424 consagran un tratamiento que, a todas luces, resulta desproporcionado en atención al fin que, en apariencia, busca cautelar:

a) En primer lugar, el límite de intereses deducible ha sido fijado en un monto equivalente al 30\% del EBITDA del ejercicio an- 
terior, pero este EBITDA se calcula a partir de elementos distintos a los de carácter financiero.

Si bien hay quien podría alegar que el empleo de indicadores de carácter tributario y no financiero se justifica en su objetividad y simple determinación, el considerado por nuestra legislación está lejos de poder servir de medida de la real capacidad de financiamiento de una empresa, y mucho menos de indicio de la existencia de transacciones encubiertas con terceros, o de pauta para conocer cuáles son los endeudamientos contraídos en términos de mercado.

No es secreto para nadie que, cuando una entidad financiera cualquiera califica una posible operación de crédito evalúa el EBITDA financiero del solicitante, no el tributario. Resulta incorrecto, entonces, crear una presunción de endeudamiento incurrido con fines elusivos con base en un concepto que en nada interviene en la aprobación de un financiamiento a un contribuyente.

Por otro lado, es, por decir lo menos, arbitrario que, en todos los casos, la capacidad de endeudamiento del contribuyente haya sido establecida en un $30 \%$ del EBITDA. Por encima de ese límite, el legislador entendería que el financiamiento, o no es necesario para la compañía, o excede su capacidad de endeudamiento. Se olvida, sin embargo, que, en la actualidad, son comunes, por no decir usuales, los esquemas de endeudamiento de proyectos, en donde se otorgan financiamientos por un número de veces que puede exceder, largamente, el EBITDA financiero completo de una compañía, pues lo que se evalúa en esos casos es la capacidad de generación de flujos futuros financieros de ésta y/o de un proyecto que busca ejecutarse con cargo al financiamiento. ¿Quiere esto decir que una empresa no podría sobre endeudarse para poder ampliar su capacidad y generar más rentas en un futuro?
No está de más señalar que en la exposición de motivos del Decreto Legislativo 1424 no existe ninguna mención que permita concluir que la fijación en un $30 \%$ del EBITDA tributario de la capacidad "adecuada" de endeudamiento financiero de una compañía tiene correlato con lo que ocurre en la realidad, en condiciones de mercado, en financiamientos con terceros. Esto, por sí solo, sería más que suficiente para cuestionar la pertinencia de esta medida.

b) En segundo lugar, cuando se revisan las exclusiones a la aplicación de esta regla, notamos que se ha excluido a los contribuyentes cuyos ingresos netos sean menores o iguales a 2,500 UIT, pero no se ha excluido a aquellos contribuyentes que, encontrándose en operaciones, buscan financiar nuevos proyectos y pueden demostrar que el financiamiento les ha sido otorgado en función de la capacidad de generación de flujos de esos proyectos, no obstante que, en ambos casos, estamos ante situaciones similares y es muy probable que, en la evaluación financiera del crédito, la institución de financiamiento haya tomado en cuenta la capacidad de generación de flujos del nuevo proyecto.

c) En tercer lugar, notamos que, en cuanto al tipo de endeudamientos excluidos, se ha considerado únicamente a los obtenidos mediante emisiones de valores mobiliarios por oferta pública en el mercado local, y se ha excluido a los obtenidos de esa misma forma en el mercado internacional, así como a los financiamientos por parte de entidades financieras locales y del exterior.

No existe ninguna justificación objetiva que permita sostener por qué solo la obtención de financiamiento mediante emisión local pública de bonos tendría propósitos no elusivos, y se descarta, de plano, otros mecanismos de financiamiento equivalentes, más aun cuando, en todos los casos, la Administración Tributaria podría siempre requerir al contribuyente o a terceros información que permita verificar la 
existencia de real necesidad y capacidad de endeudamiento. Esto, sin duda, no resiste ningún análisis de proporcionalidad.

d) Por último, como medida para morigerar los efectos de la limitación, la norma permite que los intereses que no hubieran podido ser deducidos en el ejercicio de su devengo por exceder el límite, sean adicionados a aquellos correspondientes a los cuatro ejercicios inmediatos siguientes. Esto, sin embargo, no es una solución adecuada para el problema de afectación concreta a la capacidad contributiva, que obliga a pagar, en el año de generación del interés, un impuesto mayor que el que se habría obtenido de haberse determinado sobre la real utilidad de la compañía. Como bien indican Falcón y Tella y Pulido Guerra"1,

"el hecho de que los intereses no deducidos ese año puedan computarse en los ejercicios siguientes (con el límite de 30 por 100 del beneficio operativo de ese ejercicio) no soluciona el problema porque el principio de capacidad contributiva exige gravar una capacidad actual y no futura, aparte de que puede no llegar a producirse una situación de beneficios, e incluso la norma puede llevar a la quiebra de la empresa".

Vemos, en definitiva, que la solución adoptada por nuestro legislador delegado no estuvo adecuadamente sustentada - basta la lectura de la exposición de motivos para sostenerlo-, y que no puede ser calificada de proporcional ni mucho menos de inevitable, pues, como hemos visto, podían haberse incorporado medidas que amplíen el ámbito de las exclusiones, y que permitan, caso por caso, al contribuyente demostrar la realidad del financiamiento y la inexistencia de fines elusivos detrás.

Mientras no se adopten mecanismos que permitan al contribuyente justificar, en el contexto de endeudamiento con terceros independientes, la deducción de intereses caso por caso, y mientras no se efectúen exclusiones amplias que garanticen, en definitiva, que los únicos intereses no deducibles sean aquellos de endeudamientos incurridos en situaciones ajenas a la de mercado, la solución adoptada por nuestro legislador, a todas luces, es una grave e intolerable afectación al principio de capacidad contributiva, que podría afectar no solo la forma cómo la empresa realiza sus actividades - pues limitaría su capacidad de endeudamiento no solo para llevar a cabo nuevos proyectos, sino, incluso, su capacidad de pago y generación de flujos futuros.

En un contexto como el actual, de marcada recesión y en el que incluso la deducción de los intereses de los préstamos otorgados bajo el programa Reactiva Perú se sujetará a la aplicación de esta regla, préstamos a los que, por cierto, no podría atribuírseles propósitos elusivos; es evidente que no hay justificación alguna para la aplicación de esta regla. Esperamos que el legislador la derogue, o que las autoridades judiciales declaren su inconstitucionalidad. 